Reviews

economic groups are more effective in preserving this. Those who claim that big spending does not necessarily mean big influence will find support in her finding that economic groups usually do not have the resources to exert direct modifying influence. Those who worry that economic groups can buy victory at the ballot box will find support in her finding that these groups exert subtle and indirect influence. Thus, thinking about the implications of this fine study of the populist paradox leads me to think about a paradox of social science research. Social science research and findings designed effectively to contribute to objective assessment and decision making are interpreted in ways that sustain or increase partisan debate. Time for a new study!

\title{
Critical Masses: Citizens, Nuclear Weapons Production, and Environmental Destruction in the United States and Russia, by Russell J. Dalton, Paula Garb, Nicholas P. Lovrich, John C. Pierce and John M. Whitely. Cambridge, MA: The MIT Press, 1999. 457 pp.
}

\section{Review by Michael D. Mehta, School of Policy Studies, Queen's University, Kingston, Ontario, Canada, K7L 3N6.}

With the end of the Cold War came a collective, global sigh of relief. No longer would the world's two superpowers target each other with a combined nuclear arsenal sufficient to destroy the earth several times over. However, the decades of preparing for nuclear conflict have left the United States and Russia with a daunting task; namely, dismantling the weapons of mass destruction and managing the environmental and human health risks posed by radioactive waste and weapons-grade plutonium. Critical Masses explores how citizens of both countries perceive the risks associated with nuclear weapons production and waste disposal, and how they mobilized political action to address their local concerns.

Dalton et al. do an exemplary job of comparing how citizens near the Hanford Nuclear Reservation in the State of Washington and the Mayak facility in the Southern Urals are responding to the legacy left by the Cold War. By providing us with historical background on the two regions, and survey results of environmental perceptions and their links to socio-demographic variables like age, sex and level of education, the authors give us the opportunity to see how an established democracy compares with a newly emerging democratic state in a concrete way.

Intrinsic to their analysis are certain widely held assumptions about how democracies should function. First, in a democratic society, it is presumed that public understanding is necessary for "good" government. This springs from a fundamental democratic principle that governmental policies, if they are to be viewed as legitimate, must be responsive to the will of the citizens governed by such policies. Ultimately, the "consent of the governed" is essential when peoples' health and safety are endangered by activities of the state, as the management of nuclear waste from weapons programs demonstrates. 


\section{Reviews}

Second, a crisis of legitimacy may stem from political movements that insert new values into political life. As people are attracted to new ideals of environmental quality, world peace, or a nuclear-free society, this crisis becomes a reaction to the "scientization of politics" -- an alienation from politics which has been reduced to arcane technical questions and expert decisionmaking. The concept of a "public" out there somewhere waiting to be heard from implies that those who actually make decisions do so without wide-scale support, and that such decisions are in the interest of an elite keen on maintaining control over ever scarcer resources. In a democracy, public opinion needs to be considered as a reflection of the "will of the people." Unfortunately, the role of public opinion in shaping environmental policy often plays a peripheral function in technical debates that tend to accord greater weight to "expert" scientific opinion. In political terms, the increasing concern for environmental values has meant the search for political formulations that reflect the recognition of limits and the desirability of defending a plurality of interests.

Third, although not directly linked to the erosion of democracy in post-industrial societies, reliance on technically-oriented approaches to risk assumes that liberal individualistically-oriented policy-making cannot deal with modern, communal risks. Furthermore, such an approach assumes that the production and distribution of risks is independent from economic and political forces whose actors may prefer to avoid input from the public in the form of consultation. This is where technocratic decision-making shines brightest. If public participation distracts regulators from making the "right" choices using the tools of science and scientific modes of thinking, then too much public consultation is dangerous. Conversely, by embracing technical definitions of issues, the language of political debate may become specialized and jargon-laden. Dependence on scientific experts, whose judgments are necessarily influenced by their moral beliefs and social aspirations, may replace rule by a technocratic elite for democratic process.

Fourth, the links between state and economy are particularly complex in the case of nuclear weapons programs and civilian nuclear power. Since scientists are the source of basic information on nuclear issues, technical expertise may define the language of political debate. The ability to enforce initiatives is supported by federal legislation, secrecy, the maintenance of positivistoriented ideology, and the links between regulating to protect health and environment and the promotion of the nuclear industry. However, in the United States, regulation of hazardous technology has a distinctly democratic flavor. Several nuclear power plants, including some almost completely built, have been closed or not allowed to operate due to political opposition stemming from a style of regulation which seriously takes public opinion into account. In some cases, public opposition to nuclear power has been so extreme that the granting of operating licenses was stalled for several years. Inevitably, utility companies either abandoned these unlicensed facilities or suffered bankruptcy due to long delays and extensive capital investment and mounting interest charges. This set of dynamics applies to the disposal of nuclear waste from weapons programs, but with some differences that we will consider shortly.

The authors' treatment of these issues is thorough but could use a better anchoring in the field of risk perception, communication and management. By exploring how individuals perceive various indicators of environmental quality, the authors' constructively examine some of Ronald Inglehart's work on postmaterialism and of environmental sociologists on the New Environmental Paradigm and Dominant Social Paradigm. This provides us with an opportunity to consider how the disintegration of state authority is linked to governmental responses to specific issues arising from nuclear weapons disposal. However, without a more integrated approach, like that provided by the field of risk analysis, the conclusions of such a work become two-fold in nature: they examine environmental attitudes and their relationship to theoretically inspired concepts like postmaterialism; and then assume that certain constellations of attitudes are linked to particular kinds of political activities. Without integration, debates on the management of technically complex issues become mired in technocracy. What is subsequently lacking is a framework for public participation that is sensitive to the social, economic, environmental and international dimensions of nuclear weapons disposal. 
Reviews

An example not covered in the book that ties together these dimensions comes from a proposal to export plutonium to Canada. In an effort to revive a moribund nuclear industry, Ontario Hydro and Atomic Energy Canada Limited have offered to dispose of plutonium from dismantled warheads from the United States and Russia. A fuel known as MOX (mixed oxide) is made from this plutonium and burned in nuclear reactors. Claiming the suitability of the CANDU design for this purpose, Ontario Hydro is hoping to breathe new life into its Bruce Nuclear Generating Station with a large MOX contract. The transportation, security, and human health risks from this activity have not yet been assessed. Further, no public consultation on the social acceptability of this option has been undertaken.

The MOX option is being marketed as an international responsibility on the part of Canada to help achieve the objectives of disarmament. By converting nuclear swords into electric ploughshares, an estimated 250 tonnes of plutonium from American and Russian warheads can be burned in Canadian nuclear reactors over the next 25 years. The social acceptability of this option for Canadians is unclear. With many of Canada's 21 nuclear reactors reaching the end of their engineered life span, handling large amounts of plutonium will require between 8 and 10 new reactors. No new reactors have been ordered in Canada in over 20 years and the Canadian public overwhelmingly opposes new plant construction. Additionally, the issue of nuclear waste disposal is still unresolved in Canada. Recently a proposal for a deep geologic vault in the Canadian Shield to dispose of high-level radioactive waste failed to garner public support. How can Canadians be expected to embrace the responsibility of disposing of used reactor fuel from MOX projects when the issue of waste disposal has not been adequately addressed?

Economically the use of MOX in reactors is questionable. The use of MOX as a fuel perpetuates the myth that plutonium is a commodity. Not only would reactors need considerable refurbishment to handle this new fuel mixture but an entire infrastructure for fuel fabrication and reprocessing is required. This is where the greatest weakness in the MOX argument lies. When MOX is burned in a nuclear reactor, new plutonium is produced. Expensive and hazardous reprocessing of fuel is needed to extract the remaining plutonium for another cycle through the reactor. Eventually the fuel mixture becomes economically unfeasible and the highly radioactive waste needs to be safely disposed. Instead of running through this cycle with MOX, it makes more sense to vitrify plutonium for disposal. Vitrification involves encasing plutonium in glass and burying it in safe repositories. Plutonium can be combined with high-level radioactive waste prior to vitrification so as contaminate the plutonium, thus making it unapproachable for future recovery. The MOX option keeps plutonium around for several centuries and may not help in efforts to rid the world of nuclear weapons.

The environmental impacts of the MOX option also need to be considered. Supporters of civilian nuclear power claim that electricity produced by nuclear is "clean and green" and does not contribute to atmospheric levels of carbon dioxide. If we use a life-cycle approach to analyze this claim we discover that the mining of uranium and the fabrication of fuel produces considerable environmental impacts. However, compared to the use of fossil fuels for the production of electricity nuclear is cleaner. This of course is not a fair comparison unless we also factor in the environmental impacts of the full nuclear cycle including waste disposal and reactor decommissioning. Solving existing environmental problems while creating new ones is not desirable. Clearly, instead of increasing nuclear capacity, with or without the MOX option, efforts should be made to curb energy consumption and develop and improve the efficiency of renewable energy options.

Finally, the international dimensions of the MOX option are complex. If we consider the resources required to convert plutonium to MOX and the systems needed for safe transportation and handling, plutonium has a negative economic value. Since Russia does not favor the immobilization of plutonium, MOX fabrication will be expensive. The costs of ensuring a more secure world may be higher than necessary if the MOX option is pursued. Perhaps the MOX option is nothing more than a bailout of the civilian nuclear industry and a transfer of capital to 
Reviews

Russia for the sale of plutonium. Clearly, more work needs to be done on this new wrinkle to the story of nuclear weapons disposal.

In conclusion, Critical Masses is an excellent book that should be required reading for those interested in nuclear policy, environmental issues, and social movements. Although I would have preferred to see the material integrated into a risk analysis framework and more on some of the international dynamics like the issue of MOX, the book handles an complex task with alacrity and grace.

\section{Environmentally Sustainable Economic Development, by Asayehgn Desta, Westport, CT: Praeger (1999), 236 pp.}

\section{Reviewed by Robert K. Schaeffer, Sociology, San Jose State University.}

According to Asayehgn Desta, economic development and environmental protection are not mutually exclusive goals. Instead, each depends on the other. If economic development is to be sustainable, he writes, "the environment needs to be protected. Similarly, it is axiomatic that without development there is no chance of environmental protection."(p. 12)

Proceeding from these assumptions, Desta explores a wide range of topics, showing how economic development and environmental protection can be linked to foster what he calls "environmentally sustainable economic development" (ESED). The book explores economic issues and environmental problems, examining markets, capital formation, poverty, population, women, education, multinational enterprises, technology, trade, and debt and their relation to the environment. Each chapter begins with a discussion of different theoretical approaches to these issues and argues that ESED would address many of the problems that theories and policies have encountered. Desta concludes each chapter with a case study that illustrates an important theme.

Overall, Desta provides concise, balanced, and accurate summaries of the intellectual debates and relevant literatures. The case studies are carefully chosen to make issues transparent to undergraduate readers and facilitate classroom discussion. His presentations of the Gini coefficient of inequality, China's one-child policy, the Grameen bank, AIDS in Thailand, and debt-for-nature swaps are particularly helpful, providing crucial details and historical context. This clearly organized and readable account of the issues and debates makes a real contribution to the literature on ESED, a rapidly growing field.

Throughout the book Desta maintains that ESED is both necessary and possible. Once business leaders and government officials recognize that environmental protection and economic development are joined, Desta expects that they will readily adjust their practices and policies to make it a reality. In his rather optimistic view, capitalism can be easily greened, its institutions and practices readily modified to pursue the goal of sustainable development.

Of course, environmentally sustainable economic development is a desirable goal. But some 